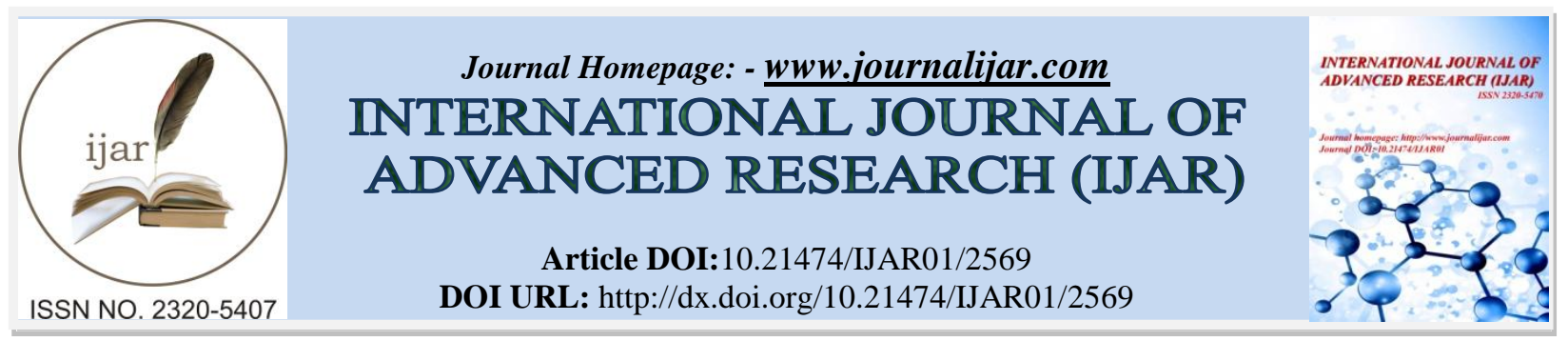

RESEARCH ARTICLE

\title{
PREVALENCE AND TYPES OF MEDICATION ERRORS AT KING ABDULLAH SPECIALIZED CHILDREN HOSPITAL, RIYADH, SAUDI ARABIA.
}

\section{Saleh I. Alomary ${ }^{1}$, Faris K. Alasmari ${ }^{1}$, Mohammad F. Aljarallah ${ }^{1}$, Hind Almodaimegh ${ }^{2}$, Lama A. Alluhidan ${ }^{1}$ and Emad Maswadi ${ }^{3}$}

1. College of Medicine, King Saud Bin Abdulaziz University for Health Sciences, Riyadh, Saudi Arabia.

2. College of Pharmacy, King Saud Bin Abdulaziz University for Health Sciences, Riyadh, Saudi Arabia.

3. Department of Medical Education, College of Medicine, King Saud Bin Abdulaziz University for Health Sciences, Riyadh, Saudi Arabia.

\section{Manuscript Info}

Manuscript History

Received: 27 October 2016

Final Accepted: 25 November 2016

Published: December 2016

Key words:-

Medication error, medication ordering,Medication error prevalence,

Patient safety, King Abdullah

Specialized Children Hospital.

\section{Abstract}

Introduction: Medication error is a serious medical concern defying the purpose of providing healthcare by causing harm and damage to the patient. The literature about medication errors in Saudi Arabia is lacking. The objective of this study is to estimate the prevalence of medication errors reported and identify their types, as well as to investigate the common factors contributing to their occurrence.

Methods: A chart-review study on all medication orders between April 2015 and January 2016 in King Abdullah Specialized Children Hospital (KASCH). Medication errors were categorized based on type of medication, location, specific event type, process stage at which the error has occurred and the contributing factors. Categorical variables were described as absolute frequencies and percentages. Multi-variant and Chi-square test were used to assess the relationship between certain variables.

Results: Of the 256,567 medication orders that were documented,792 $(0.31 \%)$ medication errors were reported.Patients between one and five years of age presented $207(30 \%)$ cases. Majority of errors occurred in hospital wards 319 (40\%), and pharmacy $167(21 \%)$. Antibiotics 169 (22\%), analgesic 75 (8\%), and antineoplastic agents75 (8\%) were the most commonly involved medication. One-hundred sixty-five $(21 \%)$ of the medication error reports involved high alert drugs. Of the medication error event types, dose-related errors were the most prevalent with $229(29 \%)$ report. The majority of medication errors occurred during the prescribing/ordering stage with367 (46\%) report. Lack of quality control dominated the contributing factors to medication errors with 595(75\%) of incidents.

Conclusion: The rate of medication error reported in $\mathrm{KASCH}$ is lower than local and international rates. The implementation of Health Information System had a role in such low rate of medication error. Utilizing data in our study can further decrease medication error rate.

Copy Right, IJAR, 2016. All rights reserved.

Corresponding Author:-Saleh I. Alomary.

Address:-College of Medicine, King Saud Bin Abdulaziz University for Health Sciences, Riyadh, Saudi Arabia. 


\section{Introduction:-}

Medication error is a serious medical concern defying the purpose of providing healthcare by inflecting harm and damage to the patient. ${ }^{1}$ The initial alarming report came from the Institute of Medicine (IOM) in 1999 report "to Err is Human: Building a safer health system" showing that medication error related deaths are between 44 to 98 thousand per year in U.S, costing an estimated figure of 17 to 29 billion US Dollars and ranking as the most common type of errors in the health care system. ${ }^{2}$

It is important to mention that a medication error is not the same as an adverse drug reaction. ${ }^{3}$ All stages of the medication utilization process (MUP) are prone to error, including packaging and nomenclature, product labeling, prescribing, order communication, dispensing, administration, monitoring, education, and use. ${ }^{4}$ Error severity can range from no harm to death according to the classification by the National Coordinating Council for Medication Error Reporting and Prevention (NCC MERP), which had established criteria for severity of medication categorizing them by the letters A (no harm) to I (death). ${ }^{4}$ By using these criteria, both medication misadventures that did not reach the patient (close call or near miss), hazardous environment that could lead to medication errors and omissions, which are the act of failing to do the right thing, ${ }^{5}$ are all considered errors and should be reported as medication errors.A major US study done in 2003 revealed high levels of omission errors in the U.S. health care system and only about $55 \%$ of patients received high-quality care across all measures. ${ }^{6}$

Prevention of medication errors has become a mandatory process that requires system-wide improvements in many organizations. ${ }^{7}$ The first strategy is by making the patients informed about their medication and involving them in the process to to minimize chances of medication error. ${ }^{2}$ Literature has supported the utilization of health information technology (HIT)to lower medication error rates and consequently enhance the quality of care. Electronic health records (EHRs) are one popular form for HIT that is commonly used. Recently, there have been an increasing number of hospitals and that are using EHRs across the globe. ${ }^{8}$ EHRs are essential to improving patient safety. ${ }^{9}$ A well-developed EHR can include variety of features that enhance medication safetyand significantly reduce the rate of medication errorthrough clinical decision support systems with computerized physician order entry (CPOE. ${ }^{7}$ Computerized physician order entry implementation resulted in a significant decrease in serious medication error rates by $55 \%$ as reported in one of the landmark trial by Bates et al. ${ }^{10}$ Furthermore, medication reconciliation is one of the methods that help in preventing medication errors ${ }^{11}$, EHR has made it easy to interface with the medication list and has made them electronically available for prescribers. ${ }^{12}$

These technologies have been proven to reduce medication errors in patients across all age groups, but perhaps the age group that will most benefits from implementing the technology are those most likely to be at risk of medication errors including the elderly and children. Medication errors in pediatric patients are common due to many reasons one of which is the need for high accuracy weight-based dose calculations further to the decimal points. ${ }^{13}$ McPhillips et al reported that $15 \%$ of a 1933 randomly selected children who received new prescriptions had potential dosing errors and $33 \%$ of dosing errors occurred in children weighing less than $35 \mathrm{~kg}$. ${ }^{14} \mathrm{Aljeraisy}$ et al found out that 56 out of every 100 medication orders in the general pediatric ward and pediatric intensive care unit (PICU) at King Abdulaziz Medical City had some error in them. ${ }^{15}$

The literature about medication errors in Saudi Arabia is lacking. The objective of this study was to estimate the prevalence of medication errors and identify their types as well as to investigate the common factors contributing to their occurrence at King Abdullah Specialized Children Hospital as hospital with a fully computerized healthcare system that includes all aspects of medical care from records and documentation to order entries.

\section{Method:-}

\section{Study design and settings:-}

This is a chart review based study of all medication orders for all patients of all age groups in King Abdullah Specialized Children Hospital (KASCH), Riyadh, Saudi Arabia between April 2015 and January 2016. KASCH is the first specialist Children's Hospital in the Kingdom of Saudi Arabia with a capacity of 600 inpatient beds not including 60 beds for pediatric emergency and trauma unite, 50 beds for Pediatric Surgical and Medical Day Care and 70 beds in Chemotherapy and Hematology Infusion Area. KASCH is a paperless digital hospital with all patient files maintained in Health Information System known as BestCare system.

\section{Study population, sample size and sampling technique:-}


By a consecutive sampling technique, the study included a total of 256,567 samples which represent all medication orders documented in KASCH BestCare System for all patients of all ages who were treated in general and specialized pediatric and adult wards, outpatient clinics, pediatric ER, pediatric High Dependence Unit, and Pediatric Intensive Care Unit in KASCH between April 2015 to January 2016. The Safety Reporting System (SRS) was used to extract all reported medication errors.

\section{Data collection and entry:-}

A data collection form was generated to collect extracted medication error reports and data from the electronic database. All variables such as demographics of the patient, drug name, high alert status of the medication, process stage of medication error, error type, location as well as the factors contributing to the error were collected.

\section{Data analysis:-}

A drug classification system was generated for all medication error reports based on drug names with the help of a $\mathrm{PhD}$. clinical pharmacist to shorten possible answers.

Statistical Package for Social Sciences (SPSS, version 20; SPSS Inc.) was used for data analysis. The categorical variables were described as absolute frequencies and percentages such as gender, high alert status and drug class. Continuous datawas summarized as mean and standard deviation such as age of the patient. Multi-variant and Chisquare test was used to assess the relation of high alert status location. All tests were considered significant when P value is less than 0.05 .

Ethical consideration:-

Data collection and handling was done after taking permission from King Abdullah International Medical Research Center (KAIMRC) and the Institutional Review Board of King Abdullah International Medical Research Center.Confidentiality was insured and personal data was not and will not be revealed.

\section{Result:-}

Overall prevalence and demographic characteristics of the patients:-

This study included 256,567 medication orders that were documented in KASCH BestCare system between April 2015 and January 2016. Of these medication order records, 792 medication errors were reported in the Safety Reporting System (SRS) at a rate of one error per 324 medication orders, or $0.31 \%$.

Malepatients presented51.3\% of affected patients.Most Patients were between one and five years of age presenting $207(30.3 \%)$ cases and $122(17.8 \%)$ cases involved patients under the age of one year.Majority of medication errors took place in hospital wards and pharmacies with $319(40.3 \%)$ and $167(21.1 \%)$ cases, respectively [Table 1].

No statistically significant difference was found between males and females in the rate of overall medication errors, HAME, drug classes, or in any specific medication error event type.

\section{Drug Class Involved:-}

Antibiotics ranked as the most commonly involved drugs in medication error reports by a significant margin with $196(22 \%)$ cases, followed by analgesic and antineoplastic agents with 75 cases $(8.4 \%)$ for each [Table 2]

Vancomycin was the most commonly reported antibioticamong antibiotic errors with 33 (17\%) report, acetaminophen in analgesic agent errors with 38 (50.7\%) report, Cytarabine\& Etoposide in antineoplastic \& chemotherapy errors with $10(13.5 \%)$ report, Enoxaparin in anticoagulanterrors with $11(50 \%)$ report, prednisone in steroid errors with 4 (19\%) report, and Medazolam in benzodiazepines errors with4 (23.5\%) reports as well.

High alert medication errors prevalence (HAME) and location:-

Of the medication error report, $165(21 \%)$ involved high alert drugs, primarilyantineoplastic and chemotherapy agents with 65(39.4\%) report, followed by high alert analgesic agents like morphine and fentanyl with $27(16.4 \%)$ report, anticoagulants with 19(11.5\%) report and total parenteral nutrition (TPN) with 19(11.5\%) report.

Hospital wards had the highest incidence of HAME with 53(32.1\%)cases. However, it presented $16.6 \%$ of the total medication errors in the same location. Adult chemotherapy infusion unit had a total incidence of 19(11.5\%) HAME 
cases. However,it presented $54.3 \%$ of the total medication error reports in the same location with a p-value of $<0.001[$ Table 3].

\section{Types of Errors:-}

Medication error specific event types ranged in frequency with dose-related errors being the most prevalent with 229(28.9\%) report, followed by medication-relatederrors (medication lost, incorrect, duplicated, package issue, and expired)with 211(26.6\%) report, and delay with 131(16.6\%) report[Table 4].

The most common forms of dose related errors were incorrect dose, extra/duplicated dose, and dose omission with $121(15.3 \%), 46(5.8 \%)$, and $30(3.8 \%)$, respectively. As for the most common medication-related error forms, medication loss preceded with $84(10.6 \%)$ report, followed by incorrect medication with $61(7.7 \%)$ report, and medication packaging issues with $43(5.4 \%)$ report [Table 4$]$.

For the high alert medications event types, 41 (24.8\%) report were dose related (incorrect, damaged, duplicated, wrong concentration or omitted), 33 (20\%) report were delays and 19(11.5\%) report were incorrect medication. There were two incidents where high alert drugs were given to the wrong patient (TPN, letrozole) and one incident of narcotic drug loss[Table 5].

\section{Medication process stages at which errors took place and contributing factors:-}

The majority of medication errors took place in the prescribing/ordering stage with 367(46.3\%) report, dispensing in $253(32 \%)$ report, and administering in 251(31.7\%) report [Table 6].

Lack of quality control dominated the factors contributing to medication error with 594(75.2\%) report, followed by the lack of staff education with $110(13.9 \%)$ report, and drug storage and delivery with $59(7.5 \%)$ report. Other contributing factors included miscommunication of drug order with $51(6.5 \%)$ report, missing drug information with $50(6.3 \%)$ report, and IT/ network problems $40(5.1 \%)$ report [Table 7].

Table 1:- Demographics of the affected patients:

\begin{tabular}{|l|l|c|c|}
\cline { 2 - 4 } \multicolumn{2}{c|}{} & $\mathrm{N}$ & $\%$ \\
\hline \multirow{4}{*}{ Gender } & Female & 346 & $48.7 \%$ \\
\cline { 2 - 4 } & Male & 364 & $51.3 \%$ \\
\cline { 2 - 4 } & Not specified & 82 & \\
\hline \multirow{5}{*}{ Age group $(17.7+23.3)$} & Less than one year & 122 & $17.8 \%$ \\
\cline { 2 - 4 } & $1-5$ & 207 & $30.3 \%$ \\
\cline { 2 - 4 } & $6-14$ & 164 & $24.0 \%$ \\
\cline { 2 - 4 } & $15+$ & 191 & $27.9 \%$ \\
\cline { 2 - 4 } & Not specified & 108 & $40.3 \%$ \\
\hline & Ward & 319 & $21.1 \%$ \\
\cline { 2 - 4 } & Pharmacy & 167 & $9.6 \%$ \\
\cline { 2 - 4 } & PICU/ICU & 76 & $8.5 \%$ \\
\cline { 2 - 4 } & Clinic & 67 & $7.6 \%$ \\
\cline { 2 - 4 } & HDU & 60 & $6.1 \%$ \\
\cline { 2 - 4 } & ER & 48 & $4.4 \%$ \\
\cline { 2 - 4 } & Adult infusion clinic & 35 & $1.6 \%$ \\
\cline { 2 - 4 } & Other & 20 & $100 \%$ \\
\cline { 2 - 4 } & Total & 792 & \\
\hline
\end{tabular}


Table 2:-Drug Classes Involved in Medication Errors:

\begin{tabular}{|c|c|c|}
\hline Drug class & $\mathbf{N}$ & $\%$ \\
\hline Antibiotic & 196 & $22.0 \%$ \\
\hline Analgesic & 75 & $8.4 \%$ \\
\hline Antineoplastic \& chemotherapy & 75 & $8.4 \%$ \\
\hline Electrolyte & 46 & $5.2 \%$ \\
\hline Supplement & 45 & $5.0 \%$ \\
\hline Fluid & 27 & $3.0 \%$ \\
\hline Anticoagulant & 22 & $2.5 \%$ \\
\hline Anticonvulsant & 22 & $2.5 \%$ \\
\hline Steroid & 21 & $2.4 \%$ \\
\hline TPN & 19 & $2.1 \%$ \\
\hline Benzodiazepine & 17 & $1.9 \%$ \\
\hline Immunosuppressant & 15 & $1.7 \%$ \\
\hline Antiviral & 14 & $1.6 \%$ \\
\hline Antihypertensive & 13 & $1.5 \%$ \\
\hline Antifungal & 12 & $1.3 \%$ \\
\hline Miscellaneous & 173 & $19.4 \%$ \\
\hline Total & 792 & $100 \%$ \\
\hline
\end{tabular}

Table 3:-Frequency and Distribution of High Alert Medication Error (HAME) by Location:

\begin{tabular}{|l|c|c|c|c|}
\hline Location & $\mathbf{N}$ & Prevalence in location* & Prevalence overall** & P-value \\
\hline Ward & 53 & $16.6 \%$ & $32.1 \%$ \\
\hline Pharmacy & 38 & $22.8 \%$ & $23.0 \%$ \\
\hline $\begin{array}{l}\text { Adult chemotherapy } \\
\text { Infusion Unit }\end{array}$ & 19 & $54.3 \%$ & $11.5 \%$ \\
\hline Clinic & 19 & $28.4 \%$ & $11.5 \%$ \\
\hline PICU/ICU & 18 & $23.7 \%$ & $10.9 \%$ \\
\hline HDU & 12 & $20.0 \%$ & $7.3 \%$ \\
\hline ER & 2 & $4.2 \%$ & $1.2 \%$ \\
\hline Other & 4 & $30.8 \%$ & $2.4 \%$ \\
\hline Total & $\mathbf{1 6 5}$ & & $\mathbf{1 0 0 . 0 \%}$ & \\
\hline
\end{tabular}

*HAME out of all medication errors in same location(HAME in location/all medication errors in same location).

** High alert medication errors out of total number of HAME (HAME in location/total n of HAME).

Table 4:-Specific Event Type For All Medication Errors:

\begin{tabular}{|c|c|c|c|}
\hline \multicolumn{2}{|c|}{ Specific Event Type } & $\mathrm{N}$ & $\%$ \\
\hline \multirow{5}{*}{$\begin{array}{l}\text { Dose-related } \\
\text { errors }\end{array}$} & Dose incorrect & 121 & $15.3 \%$ \\
\hline & Dose extra/duplication & 46 & $5.8 \%$ \\
\hline & Dose omitted & 30 & $3.8 \%$ \\
\hline & Dose incorrect concentration/strength & 20 & $2.5 \%$ \\
\hline & Dose damaged/deteriorated & 12 & $1.5 \%$ \\
\hline \multicolumn{2}{|l|}{ Total } & 229 & $28.9 \%$ \\
\hline \multirow{5}{*}{$\begin{array}{l}\text { Medication- } \\
\text { related error }\end{array}$} & Medication-lost & 84 & $10.6 \%$ \\
\hline & Medication-incorrect & 61 & $7.7 \%$ \\
\hline & Medication-package issue & 43 & $5.4 \%$ \\
\hline & Duplicate therapy & 15 & $1.9 \%$ \\
\hline & Medication-expired/outdated & 8 & $1.0 \%$ \\
\hline \multicolumn{2}{|l|}{ Total } & 211 & $26.6 \%$ \\
\hline \multicolumn{2}{|l|}{ Delay } & 131 & $16.6 \%$ \\
\hline \multicolumn{2}{|c|}{ Frequency-incorrect } & 34 & $4.3 \%$ \\
\hline \multicolumn{2}{|c|}{ Duration-incorrect } & 29 & $3.7 \%$ \\
\hline \multicolumn{2}{|c|}{ Allergy-known-patient ordered/received medication } & 21 & $2.7 \%$ \\
\hline \multicolumn{2}{|c|}{ Dosage form- incorrect } & 10 & $1.3 \%$ \\
\hline
\end{tabular}




\begin{tabular}{|l|c|c|}
\hline Wrong Patient & 10 & $1.3 \%$ \\
\hline Incomplete Order & 9 & $1.1 \%$ \\
\hline Other & 108 & $13.5 \%$ \\
\hline Net total & $\mathbf{7 9 2}$ & $\mathbf{1 0 0 . 0 \%}$ \\
\hline
\end{tabular}

Table 5:-Specific Event Types For High Alert Medication Errors (HAME):

\begin{tabular}{|c|c|c|c|}
\hline \multicolumn{2}{|c|}{ Specific event type for HAME } & $\mathrm{N}$ & $\%$ \\
\hline \multicolumn{2}{|l|}{ Delay } & 33 & $20 \%$ \\
\hline \multirow{6}{*}{$\begin{array}{l}\text { Dose related } \\
\text { errors }\end{array}$} & Dose incorrect & 16 & $9.7 \%$ \\
\hline & Dose omitted & 9 & $5.5 \%$ \\
\hline & Dose extra/duplication & 7 & $4.2 \%$ \\
\hline & Dose damaged/deteriorated & 5 & $3 \%$ \\
\hline & Dose incorrect concentration & 4 & $2.4 \%$ \\
\hline & Total & 41 & $24.8 \%$ \\
\hline \multirow{6}{*}{$\begin{array}{l}\text { Medication-related } \\
\text { errors }\end{array}$} & Incorrect medication & 18 & $10.9 \%$ \\
\hline & Medication package issue & 11 & $6.7 \%$ \\
\hline & Medication duplication & 4 & $2.4 \%$ \\
\hline & Medication lost & 10 & $6.1 \%$ \\
\hline & Wrong patient & 2 & $1.2 \%$ \\
\hline & total & 45 & $27.3 \%$ \\
\hline \multicolumn{2}{|c|}{ Patient received medication despite known allergy } & 2 & $1.2 \%$ \\
\hline \multicolumn{2}{|l|}{ Incorrect frequency } & 7 & $4.2 \%$ \\
\hline \multicolumn{2}{|l|}{ Incomplete order } & 6 & $3.6 \%$ \\
\hline \multicolumn{2}{|c|}{ Medication discontinuation } & 4 & $2.4 \%$ \\
\hline \multicolumn{2}{|l|}{ Narcotic broken } & 4 & $2.4 \%$ \\
\hline \multicolumn{2}{|l|}{ Incorrect duration } & 3 & $1.8 \%$ \\
\hline \multicolumn{2}{|c|}{ Dosage form incorrect } & 3 & $1.8 \%$ \\
\hline \multicolumn{2}{|c|}{ Medication given without order } & 1 & $0.6 \%$ \\
\hline \multicolumn{2}{|l|}{ Other } & 16 & $9.7 \%$ \\
\hline \multicolumn{2}{|l|}{ Net total } & 165 & $100 \%$ \\
\hline
\end{tabular}

Table 6:-Medication process stages at which errors took place.

\begin{tabular}{|l|c|c|}
\hline Process stage & $\mathrm{N}$ & $\%$ \\
\hline Prescribing/ordering & 366 & $46.3 \%$ \\
\hline Administering & 251 & $31.7 \%$ \\
\hline Dispensing & 258 & $32.6 \%$ \\
\hline Storage & 97 & $12.3 \%$ \\
\hline Transcribing & 55 & $7 \%$ \\
\hline Monitoring & 35 & $4.4 \%$ \\
\hline Purchasing & 4 & $0.5 \%$ \\
\hline Patient Education & 5 & $0.6 \%$ \\
\hline
\end{tabular}

Table 7:- Factors contributing to medication error

\begin{tabular}{|l|c|c|}
\hline Contributing factors & $\mathbf{N}$ & $\mathbf{\%}$ \\
\hline Lack of Quality Control & 594 & $75.2 \%$ \\
\hline Lack of Staff Education & 110 & $13.9 \%$ \\
\hline Drug Storage or Delivery & 59 & $7.5 \%$ \\
\hline Miscommunication of Drug Order & 51 & $6.5 \%$ \\
\hline Drug Information Missing & 50 & $5.3 \%$ \\
\hline IT/Network problems & 40 & $9.1 \%$ \\
\hline Others & 71 & $9.0 \%$ \\
\hline
\end{tabular}




\section{Discussion:-}

In this study we measured the incidence of medication errors in KASCH and found out that to be 792 errors at rate of0.31\%.In a study conducted at an Australian children's hospital over a 4-year period, the reported overall medication error rate was the same as the rate reported in our study of $0.31 \% .{ }^{16} \mathrm{Al}$ Jeraisy et al. reported the rate of medication errors to be 56 per 100 medication orders among inpatient pediatric in a tertiary care center in Saudi Arabia. ${ }^{15}$ Similar high rates were reported for the pediatric population in Egypt, Iran, and West Ethiopia at $78 \%$, $53 \%$, and $75 \%$ respectively. ${ }^{18,19}$ Ghaleb et al. reported $13.2 \%$ medication administration errors in the UK. ${ }^{20}$ Aljadhy et al. found medication errors to be 32.36 per 100 medication orders among adult patients in four hospitals in Saudi Arabia. ${ }^{21}$ The rate of prescribing medication errors in the Middle East ranged between $7.1 \%$ and $90.5 \%$ (lowest in Saudi Arabia, highest in Bahrain). ${ }^{19}$ The rate of the errors reported in our study was low compared to rates in the United States, UK, and Pakistan, where the rates of reported medication errors were $6.9 \%, 3 \%$, and $5.5 \%$, respectively. $^{22,23}$ The rate, however, was similar to the rate reported by Alshaikh et al. at $0.4 \%$ in a hospital in Saudi Arabia. $^{24}$

Prevalent types of medication errors were delay, incorrect dosage, and loss of medication. Most of medication errors occurred during the prescribing/ordering stage and the administering stage. According to a study done by Alsulamiet al. that included 45 studies from the middle east, most common types of prescribing errors reported were incorrect dose (with an incidence rate from $0.15 \%$ to $34.8 \%$ of prescriptions), wrong frequency and wrong strength. ${ }^{19}$

Commonly involved drug classes were antibiotics, analgesics and antineoplastic agents which were similar to those reported by other studies. ${ }^{19,25}$ Higher error report rates of high-alert medications is an indicator of better error surveillance. ${ }^{26}$ Around one-fifth of the medication errors in this study involved high alert drugs, mostly antineoplastic agents, high alert analgesic agents, and anticoagulants.

The lack of quality control was found to be the most contributing factor in our study in around $75 \%$ of the cases followed by lack of staff education in around 14\%. Miscommunication following patients' transfer across hospital facilities and the lack of following policies and procedures were the factors reported by Manias et al with incidence rate of $33.7 \%$ and $22.4 \%$, respectively. Drug characteristics, administration time, heavy workload, and misinterpretation of the order were also suggested as contributing factors. ${ }^{16}$

Upon review of the literature we found that dose related errors constitute the majority of medication errors, which was also the case in our study. ${ }^{15,16,25,27}$ This warrants implementation and evaluation ofinterventionsaiming to eliminate these errors and maximize patient safety. MacKay et aldemonstrated a decrease in dose-related medication errors in pediatrics by intravenous and oral medication standardization. This decreased workload, wastage, improved outcome, and lowered cost. ${ }^{28}$ Barrier et al suggested standardizing the dosing instruments and units. ${ }^{29} \mathrm{We}$ recommended establishing measures to reduce dose related errors; their efficacy should be determined in further studies.

Finally, these lower rates of reported medication errors could raise the suspicion of underreporting which is a serious obstacle that needs to be addressed. However, this could have been the advantage of utilizing Computerized Physician Order Entry (CPOE) and pharmacist review of prescription as their implementation has shown to decrease medication errors by half. ${ }^{30,}{ }^{31}$ In Australia, $86 \%$ of adverse events related to medical errors, including medication errors, were not reported. ${ }^{32}$ Mansouri et al. stated the barriers for underreporting to be personal fears, administrative barriers, and the reporting process. ${ }^{33}$ Reasons for underreporting in the "Hospital incident reporting systems do not capture most patient harm" report were the absence of perceptible error, accustomedness to a common occurrence, expectation of side effects, and high frequency of occurrences. ${ }^{32}$ Studies exploring underreporting causes in Saudi Arabia are needed.

\section{Limitations:-}

This study did not measure the prevalence of medication error in each and every specific location or department of the hospital. Some errors that did not inflect any serious harm on patients or alarm administrationmay have been underreported. The study did not include the medication error related patient-specific outcome. 


\section{Conclusions:-}

In conclusion, Medication errors reported in King Abdullah Specialized Children Hospital, Riyadh, Saudi Arabia were less than the international figures. Most commonly involved drug classes were antibiotics, analgesics, and antineoplastic agents. Prevalent types of medication errors were delay, incorrect dose, and loss of medication. Most of the medication errors occurred during the prescribing/ordering stage and the administering stage. Utilizing data in our study to develop strategies that target contributing factors as well as the setting where medication error occur frequently could further decrease its rate. This study can serve as a benchmark to evaluate the progress of medication safety upon implementation of future strategies and measures.

\section{References:-}

1. Agrawal A. Medication errors: prevention using information technology systems. Br J Clin Pharmacol. 2015;57(6):681-6.

2. Institute of Medicine. To err is human: building a safer health system. National Academy of Sciences; 1999. Available from: http://www.ncbi.nlm.nih.gov/books/NBK2673/

3. Britten N. Medication errors: the role of the patient. Br J ClinPharmacol,(2009); 67(6): 646-50. http://doi.org/10.1111/j.1365-2125.2009.03421.x

4. National Coordination Council for Medication Error Reporting and Prevention. Types of medication errors [Internet]. 2014 [cited 7 December 2015]. Available from: http://www.nccmerp.org/types-medication-errors

5. Agency for Healthcare Research and Quality. Patient Saftey Network. Glossaries of medication errors. [Internet]. 2015 [cited 26 March 2016]. Available from: https://psnet.ahrq.gov/glossary

6. McGlynn E, Asch S, Adams J, Keesey J, Hicks J, DeCristofaro A et al. The quality of health care delivered to adults in the United States. N Engl J Med. 2003; 348(26):2635-45.

7. Forni A, Fanikos J, Chu H. Technology utilization to prevent medication errors. Curr Drug Saf. 2010;5:13-8.

8. Kennebeck S, Spooner A, Farrell M, Timm N. Impact of electronic health record implementation on patient flow metrics in a pediatric emergency department. J Am Med Inform Assoc. 2012;19:443-7.

9. Sittig D, Singh H. Electronic health records and national patient-safety goals. N Engl J Med 2012;367:1854-60.

10. Bates DW, Leape LL, Cullen DJ, Laird N, Petersen LA, Teich JM, et al. Effect of computerized physician order entry and a team intervention on prevention of serious medication errors. JAMA. 1998;280:1311-6.

11. Cornu P, Steurbaut S, Leysen T, Baere E. Effect of medication reconciliation at hospital admission on medication discrepancies during hospitalization and at discharge for geriatric patients. Ann Pharmacother. 2012;46:484-94.

12. Medication Reconciliation Resource Center | HIMSS Continuity of Care [Internet]. Himss.org. 2016 [cited 26 March 2016]. Available from: http://www.himss.org/library/medical-practice-information-systems/carecoordination/emr-library

13. Joint Commission. Preventing pediatric medication errors [Internet]. 2008 [cited 26 March 2016]. Available from: http://www.jointcommission.org/assets/1/18/SEA_39.PDF

14. McPhillips HA, Stille CJ, Smith D, Hecht J, Pearson J, Stull J, et al. Potential medication dosing errors in outpatient pediatrics. J Pediatr. 2005;147:761-7.

15. Al-Jeraisy M, Alanazi M, Abolfotouh M. Medication prescribing errors in a pediatric inpatient tertiary care setting in Saudi Arabia. BMC Res Notes. 2011;4:1-6.

16. Manias E, Kinney S, Cranswick N, Williams A. Medication errors in hospitalised children. Journal of Paediatrics and Child Health [Internet]. 2013 [cited 4 December 2016];50(1):71-77. Available from: http://onlinelibrary.wiley.com/doi/10.1111/jpc.12412/abstract;jsessionid=F5EBF76EE0125036292143ADA8B A9145.f03t03

17. Aronson J. Medication errors: definitions and classification. Br J Clin Pharmacol. 2009;67(6):599-604

18. Dedefo M, Mitike A, Angamo M. Incidence and determinants of medication errors and adverse drug events among hospitalized children in West Ethiopia. BMC Pediatrics [Internet]. 2016 [cited 4 December 2016];16(1). Available from: https://www.ncbi.nlm.nih.gov/pubmed/27387547

19. Alsulami Z, Conroy S, Choonara I. Medication errors in the Middle East countries: A systematic review of the literature. European Journal of Clinical Pharmacology [Internet]. 2012 [cited 4 December 2016];69(4):9951008. Available from: https://www.ncbi.nlm.nih.gov/pubmed/23090705

20. Ghaleb M, Barber N, Franklin B, Wong I. The incidence and nature of prescribing and medication administration errors in paediatric inpatients. Archives of Disease in Childhood [Internet]. 2010 [cited 4 December 2016];95(2):113-118. Available from: http://adc.bmj.com/content/95/2/113.long 
21. Aljadhey H, Mahmoud M, Ahmed Y, Sultana R, Zouein S, Alshanawani S et al. Incidence of adverse drug events in public and private hospitals in Riyadh, Saudi Arabia: the (ADESA) prospective cohort study. BMJ Open [Internet]. 2016 [cited 4 December 2016];6(7):e010831. Available from: https://www.ncbi.nlm.nih.gov/pmc/articles/PMC4947792/

22. Dean BS, Allan EL, Barber ND, Barker KN. Comparison of medication errors in an American and a British hospital. Am J Health Syst Pharm. 1995 Nov 15;52(22):2543-9. PubMed PMID: 8590237.

23. Khowaja K, Nizar R, Merchant RJ, Dias J, Bustamante-Gavino I, Malik A. A systematic approach of tracking and reporting medication errors at a tertiary care university hospital, Karachi, Pakistan. Ther Clin Risk Manag. 2008 Aug;4(4):673-9. PubMed PMID: 19209247; PubMed Central PMCID: PMC2621376.

24. Alshaikh M, Mayet A, Aljadhey H. Medication Error Reporting in a University Teaching Hospital in Saudi Arabia. Journal of Patient Safety [Internet]. 2013 [cited 4 December 2016];9(3):145-149. Available from: http://meta.wkhealth.com/pt/pt-core/template-journal/lwwgateway/media/landingpage.htm?issn=1549$8417 \&$ volume $=9 \&$ issue $=3 \&$ spage $=145$

25. Samsiah A, Othman N, Jamshed S, Hassali M, Wan-Mohaina W. Medication errors reported to the National Medication Error Reporting System in Malaysia: a 4-year retrospective review (2009 to 2012). European Journal of Clinical Pharmacology [Internet]. 2016 [cited 6 December 2016];72(12):1515-1524. Available from: https://www.ncbi.nlm.nih.gov/pubmed/27637912

26. Crawford, S.Y., Cohen, M.R. \&Tafesse, E. Journal of Medical Systems (2003) 27: 543. doi:10.1023/A:1025985832133

27. Salmasi S, Khan T, Hong Y, Ming L, Wong T. Medication Errors in the Southeast Asian Countries: A Systematic Review. PLOS ONE [Internet]. 2015 [cited 4 December 2016];10(9):e0136545. Available from: http://journals.plos.org/plosone/article?id=10.1371/journal.pone.0136545

28. MacKay, Mark W. et al. "Improving Pediatric Outcomes through Intravenous and Oral Medication Standardization." The Journal of Pediatric Pharmacology and Therapeutics: JPPT 14.4 (2009): 226235. PMC. Web. 4 Dec. 2016.

29. Rinke M, Bundy D, Velasquez C, Rao S, Zerhouni Y, Lobner K et al. Interventions to Reduce Pediatric Medication Errors: A Systematic Review. PEDIATRICS [Internet]. 2014 [cited 4 December 2016];134(2):338360. Available from: http://pediatrics.aappublications.org/content/134/2/338.long

30. Radley D, Wasserman M, Olsho L, Shoemaker S, Spranca M, Bradshaw B. Reduction in medication errors in hospitals due to adoption of computerized provider order entry systems. Journal of the American Medical Informatics Association [Internet]. 2013 [cited 4 December 2016];20(3):470-476. Available from: http://jamia.oxfordjournals.org/content/20/3/470.long

31. Nuckols T, Smith-Spangler C, Morton S, Asch S, Patel V, Anderson L et al. The effectiveness of computerized order entry at reducing preventable adverse drug events and medication errors in hospital settings: a systematic review and meta-analysis. Systematic Reviews [Internet]. 2014 [cited 4 December 2016];3(1). Available from: https://systematicreviewsjournal.biomedcentral.com/articles/10.1186/2046-4053-3-56

32. Hospital incident reporting systems do not capture most patient harm: OIG, Department of Health and Human Services. 2012. Available at: http://oig.hhs.gov/oei/reports/oei-06-09-00091.asp.

33. Mansouri A, Ahmadvand A, Hadjibabaie M, Javadi M, Khoee SH, Dastan F, Gholami K. A review of medication errors in iran: sources, underreporting reasons and preventive measures. Iran J Pharm Res. 2014 Winter;13(1):3-17. Review. PubMed PMID: 24734052; PubMed Central PMCID: PMC3985240. 